\title{
Advanced Placement Course Credit and Undergraduate Student Success in Gateway Science Courses
}

Christian Fischer, ${ }^{1,}$ Eben Witherspoon, ${ }^{2}$ Ha Nguyen, ${ }^{3}$ Yanan Feng, ${ }^{4}$ Stefano Fiorini, ${ }^{4}$ Paulette Vincent-Ruz, ${ }^{5}$ Chris Mead, ${ }^{6}$ William Bork, ${ }^{7}$ Rebecca L. Matz,${ }^{7,8}$ Christian Schunn ${ }^{2}$

${ }^{1}$ Hector Research Institute of Education Sciences and Psychology, University of Tübingen

${ }^{2}$ Learning Research \& Development Center, University of Pittsburgh

${ }^{3}$ School of Education, University of California, Irvine

${ }^{4}$ College of Arts and Sciences, Indiana University

${ }^{5}$ College of Literature, Science, and the Arts, University of Michigan, Ann Arbor.

${ }^{6}$ School of Earth and Space Exploration, Arizona State University.

${ }^{7}$ Hub for Innovation in Learning and Technology, Michigan State University

${ }^{8}$ Center for Academic Innovation, University of Michigan, Ann Arbor

*Corresponding author: christian.fischer@uni-tuebingen.de 


\begin{abstract}
Approximately two million students take Advanced Placement (AP) examinations annually. However, departmental policies that allow students to replace introductory courses with AP credit greatly vary within and across universities, even across relatively similar universities. This study examines the impact of AP credit policies on subsequent course success in Biology, Chemistry, and Physics at six large public research universities $(\mathrm{N}=48,230$ students). Examining average treatment effects for students skipping college courses using inverse-probability weights with regression adjustment, we found that students who skipped actually performed similarly well or better in subsequent courses than students who did not skip, even in contexts where lower AP scores were accepted. We also discovered wide variation in percentage of students who chose to skip when meeting their local policies. Therefore, to reduce unnecessary coursework that is burdensome for both students and universities, we suggest that departments consider modifying AP credit policies and that advisors consider encouraging students to skip when they have eligible AP scores.

Keywords: AP Program, Higher Education, Science Education, Gateway Courses, Student Success, Educational Policy
\end{abstract}




\section{Advanced Placement Course Credit and Undergraduate Student Success in Gateway Science Courses}

Success in postsecondary education and pathways in the labor market are uncertain for many students in science, technology, engineering, and mathematics (STEM) fields (AllenRamdial \& Campbell, 2014; Olson \& Riordan, 2012). About half of all students seeking bachelor's degrees in STEM between 2003 and 2009 left the STEM fields by 2009 (Chen, 2013). In particular, students historically marginalized in college environments are at risk of leaving STEM fields (Griffith, 2010). Efforts to address this problem often center individual-level approaches like improving students' learning experiences and their college-readiness (Maltese \& Tai, 2011; Means et al., 2016), with the Advanced Placement (AP) program being viewed as a college readiness indicator for student success in gateway courses (Cromwell et al., 2013).

College Board's AP program is a large and complex system with many intended and unintended effects. In 2020, approximately 2.6 million students completed more than 4.7 million AP examinations (The College Board, 2020b). Most directly, AP courses provide rigorous, college-level coursework to high school students. Increased participation in AP has the potential to improve educational quality and expand access to higher education (Burnett \& Burkander, 2021). The intention is that university departments should allow students to replace introductory college courses with AP credit if the students obtain a passing score (Cromwell et al., 2013), thereby accelerating progression to degree, increase retention and course concentration in STEM and reducing the costs of college (Gurantz, 2021). However, AP credit policies substantially vary across universities and even by department within universities (Duffy, 2010; Jagesic \& Wyatt, 2018; Wyatt et al., 2018), sometimes requiring higher minimum thresholds of 4 or 5, and sometimes not accepting the equivalence at all. Some of these policies and variation in how 
students take advantage of AP credit could further grow systemic inequities, especially given concerns about access to AP coursework (Kanno \& Kangas, 2014; Price, 2020). However, structural-level policies and systemic inequities of awarding college-level credit, which are a focus of this study, are seldomly studied.

\section{Background}

\section{Impacts of the AP program}

Several studies have examined associations of students' AP program participation with college-level outcomes. For instance, Chajewski and colleagues (2011) found an association of AP participation with higher rates of college enrollment. When examining introductory college course performance, students who earn passing AP scores tend to perform better compared to students who did not take AP examinations (Sadler \& Sonnert, 2010; Sadler \& Tai, 2007). Similarly, AP course-taking and AP exam performance are associated with higher first-year college GPA, higher graduation rate, and shorter time-to-degree (Ackerman et al., 2013; Evans, 2019; Scott et al., 2010; Smith et al., 2017). AP participation and success are also associated with college major choices and careers interests (Avery et al., 2016; Evans, 2019; Warne et al., 2019). Notably, the higher a student's score on an AP exam, the greater the probability of majoring in the corresponding subject (Avery et al., 2016; Gurantz, 2021).

Especially relevant to awarding credit for AP courses is performance in later courses; even when students have earned passing scores on AP exams, university faculty and administrators worry that students will struggle in later courses if they do not experience the equivalent gateway courses at the given university. Research on the impacts of AP credit policies with subsequent course success is, however, currently limited to four non-peer-reviewed College Board reports: 
Wyatt and colleagues (2018) examined 14 AP courses for students at 93 colleges. Mean comparisons without any covariates indicated that students who earned AP credit and skipped the introductory college courses tended to score higher in subsequent courses across all subject areas compared to students who did not take the AP exam but completed the respective introductory college courses. Jagesic and Wyatt (2018) conducted a complementary study examining 10 other AP exams across 50 colleges. Using the same mean comparison approach without covariates, students who earned AP credit and skipped the introductory college course tended to score higher in subsequent courses across most subject areas compared to students who did not take the AP exam but completed the respective introductory college courses. Using a somewhat more sophisticated methodology, Morgan and Klaric (2007) examined data of 10 AP exams from 72,457 first-year undergraduate students at 27 colleges. Regression analysis, using students' SAT score as the sole covariate, indicated that students who earned AP credit had significantly higher course grades in subsequent courses for seven out of the ten examined AP exams compared to students who did not take the AP exam but completed the respective introductory college courses. Earning a 4 was usually sufficient to show a positive effect, and sometimes even a 3 showed a positive effect. However, this study did not use high school performance as a covariate, which is a major limitation as it represents a stronger predictor of college performance than SAT scores (Galla et al., 2019). Another study explored data from a single university using simple regression controls of SAT scores and high school rank (Keng \& Dodd, 2008). This study found that students who earned AP credit generally did better in later same-subject coursework for 9 of the 10 AP exams explored. However, when focusing on twocourse gateway sequences, students in Biology did worse in the second course when compared with students who took the first gateway course at the university, students in English 
Composition performed equally well, and students in Calculus did somewhat better in the subsequent gateway course. Together, the studies present a mixed story about the impact of AP credit on subsequent course performance.

\section{Educational equity and the AP program}

Although studies have demonstrated potential benefits of AP program participation for students' college careers, differential access to quality AP program can exacerbate unequal learning opportunities to students (Price, 2020). Studies have shown that access to AP courses across the nation and performance on AP examinations are stratified by race and class (Kanno \& Kangas, 2014; Klugman, 2013; Schneider, 2009), and as such can be related to racial segregation and income inequality (Card \& Rothstein, 2007; Tienken, 2012). Inequitable learning opportunities in AP courses are often attributed to shortages of qualified and experienced teachers, and an overall lower quality of instruction in schools with higher percentages of historically underserved and marginalized students (Hallett \& Venegas, 2011; Kyburg et al., 2007; Taliaferro \& DeCuir-Gunby, 2008).

In response, the College Board has engaged in efforts to mitigate these inequalities, for instance, by increasing access to the AP program (Conger et al., 2009; Roegman \& Hatch, 2016). Moreover, many school systems and several states have allocated substantial funds to pay students' test fees to further improve access (The College Board, 2020a). AP facilitates students access to institutional and less risky educational fund as showed at one of the institutions in this study (Lin et al., 2020). Further, the fiscal burden of unnecessary course-taking in college will be felt most severely by students from lower-income families. Therefore, to better shape policies that impact historically underserved students who do currently earn AP credits and to also shape 
future policies in order to expand access to AP, this study examines key aspects of advanced placement decisions for students.

\section{Research Questions}

Institutions of Higher Education become the gatekeepers of the potential benefits that earning a successful AP score affords students. This is affected by a combination of effective and fair credit policies, and student advising. This study represents the first independent and crossinstitutional effort to examine the impact of replacing introductory science courses with AP credit on subsequent course performance applying advanced statistical research methods. As equity is a central concern in undergraduate science policies, we also carefully examine who currently tends to have qualifying AP scores among those attending public research institutions in STEM programs and who has tended to claim AP credit when eligible, a potentially important but previously unexamined topic. Specifically, this study is guided by three research questions (RQs) focused on students enrolled in introductory science course sequences:

RQ1: What student characteristics are associated with having earned AP scores that qualify for skipping introductory science courses?

RQ2: What student characteristics are associated with skipping introductory science courses for students who have earned skip-eligible AP scores?

RQ3: What are the impacts of replacing an introductory course with AP course credit on subsequent science course grades?

\section{Methods}

\section{Data Sources and Sample}

This study was conducted at six large public research universities in the United States. We focused on AP Biology, AP Chemistry, and AP Physics C: Mechanics as their corresponding 
college-level courses are central to most undergraduate STEM degrees. We focused on the first two courses in each courses series irrespective of whether institutions were on a quarter or semester schedule (Biology: Cell Biology and Evolution and Ecology; Chemistry: General Chemistry sequence; Physics, Force and Motion, and Electricity and Magnetism).

This study only included degree-seeking students on their first attempt taking courses in these three large science gateway course series. Also, we excluded transfer students, visiting students, and students who did not attend a U.S. high school as they were unlikely to have had AP experiences or to have participated in these science course sequences. This led to a full analytical sample of 48,230 students and 14 courses across the six institutions.

\section{Measures}

The core dependent variables indicated whether a student earned an AP score that allows for skipping the first course in the course sequence (RQ1), whether a skip-eligible student actually skipped the first course in the course sequence (RQ2), and a continuous measure describing second course performance on the typical 0-4 grade scale (RQ3).

Independent variables for RQs 1 and 2 included dichotomous variables indicating students' self-reported sex (1: female, 0: male), first-generation college student status (1: neither parent/guardian holds a bachelor's degree, 0: at least one parent/guardian holds a bachelor's degree), and low-income status (1: flagged as low-income based on either family household income and household size using $185 \%$ of the U.S. poverty line or Pell grant eligibility; 0: not flagged as low-income). We also included a categorical variable representing students' selfreported racial/ethnical background (0: White, 1: Under-represented Minority (URM), 2: Asian; with White being the reference group as they were the largest group and typically performed in a middling level). In the case of multiple racial/ethnic backgrounds, White/Asian were grouped 
with Asian, and all other combinations were grouped with URM given how race/ethnicity is commonly experienced in the U.S. (Asai, 2020). In addition, we included continuous variables that capture prior academic achievement in high school including students' high school GPA, mathematics proficiency (highest score on math ACT/SAT exam; ACT scores were converted to SAT scores using common concordance tables), and English proficiency (highest score on Reading ACT/SAT exam). The year of the course was included as covariate to remove variance related to features groups of students in those courses that year (e.g., grade curves).

For RQ3, the core independent variable represented a dichotomous variable indicating whether a student skipped the first course in the course sequence. The independent variables described for RQs 1 and 2 served in RQ3 as covariates and matching variables for creating propensity score measures.

Table 1 provides descriptive information for all variables at each institution. Missingness across variables was very low (i.e., usually below 10\%) and assumed to be completely random. Correspondingly, all analyses were conducted using list-wise deletion as the missing data strategy.

[Table 1 about here]

\section{Statistical Analysis}

For RQ1, we conducted simple bi-serial correlations with demographic variables and a binary variable indicating if a student earned a skip-eligible score at their respective institution to identify whether different groups of students were more or less likely to be skip eligible. Afterwards, we conducted multiple logistic regression models with the same demographic variables and additional high school performance and achievement variables to determine the influence of prior performance measures for earning skip-eligible AP scores. Notably, logistic 
regression analyses were only conducted for institutions and disciplines with sufficient variation on the dependent variable (i.e., at least 100 skip-eligible students), which led to the exclusion of two institutions for Biology, Chemistry, and Physics each.

For RQ2, we limited the dataset to students who earned a skip-eligible score at their corresponding institution and discipline. We then conducted multiple logistic regression analyses to examine whether those same demographic and performance variables were related to students' propensity to choose to skip the course once they had earned an eligible score. In these models, we also controlled for the students' cohort (i.e., matriculation year) to remove the variance that was correlated with the particular group of students matriculating across years. Again, logistic regression analyses were only conducted for institutions and disciplines with sufficient variation on the dependent variable, which led to the exclusion of three institutions for Biology, three institutions for Chemistry, and five institutions for Physics, respectively.

For RQ3, we created a matched sample of students using propensity scores as inverse probabilities of treatment weights for the regression models (Austin, 2011). Propensity scores were calculated as the probability estimates of a student skipping the introductory course, accounting for demographic and performance variables. Researchers have applied propensity score matching methods to reduce sample biases and provide more robust estimates in nonexperimental settings where there may exist confounding differences between the comparison groups (Dehejia \& Wahba, 2002). Using this propensity weighting approach, we determined the effects of skipping on course grade, controlling for demographics and prior performance for (a) the full sample of students and (b) students with skip-eligible AP scores. Notably, we only conducted analyses for institutions and disciplines that exhibited sufficient variation on the matching term (i.e., fewer than $90 \%$ of those who were eligible to skip actually skipped the first 
course), which led to an exclusion of three institutions for Biology, two institutions for Chemistry, and four institutions for Physics, respectively.

\section{Results}

\section{Student participation and success in the AP program (RQ1)}

Student participation in the three AP exams varied widely across institutions within each discipline. The percent of students having AP experiences varied from $24 \%$ to $54 \%$ in Biology, $14 \%$ to $40 \%$ in Chemistry, and $12 \%$ to $32 \%$ in Physics. Overall, having AP experiences ranged from 1 in 8 students to over half of students. Similarly, departmental policies awarding AP credit to replace introductory courses varied greatly across institutions and disciplines (Table 2). Out of the six institutions included in our study, three had AP credit policies allowing students to skip the first course in all three of the Biology, Chemistry, and Physics courses sequences, and the other three institutions allowed students to skip courses in two of the three studied disciplines. Notably, even for institutions awarding AP credit, the corresponding thresholds varied across disciplines, with three institutions awarding credit for a 3 on an AP exam (one institution for Biology, two institutions for Chemistry, zero institutions for Physics). All six institutions awarded AP credit for a 4 on at least one AP exam (four institutions for Biology, two institutions for Chemistry, two institutions for Physics) and three institutions only for a 5 on one AP exam (zero institutions for Biology, one institution for Chemistry, three institutions for Physics). In sum, even for a relatively homogeneous set of large public research institutions, we find no agreement on departmental AP policies.

[Table 2 about here] 
Correlations between student performance on AP exams and demographic factors indicate that first-generation college student status, low-income status, and female sex tend to be negatively correlated with earning skip-eligible AP scores across disciplines and institutions (Figure 1A). Interestingly, there are no significant correlations between racial/ethnic minority status and students' AP performance for Chemistry and Physics, and this correlation tends to be negative for Biology across institutions. Importantly, however, these demographic correlations are all small: a correlation of -0.1 means only $1 \%$ of the variance is explained by the demographic variable. The strength of the correlation appeared to be unaffected by institutional cut-offs for accepting AP credit. Having small-sized effects in the relationships between AP performance and demographic factors is consistent with prior research regarding the localization of inequities which appeared to emerge upstream (Price, 2020). For example, it appears that inequities of AP enrollments (e.g., large gender differences in AP Physics enrollments) manifests primarily at earlier steps: in who enrolls at these institutions and follows science pathways.

[Figure 1 about here]

Academic performance predictors of high school GPA (HS GPA) and SAT performance were predictive of earning skip-eligible AP scores. The meta-regressions coefficients (Figure 1B), which control for demographic variables to estimate the unique associations with HS GPA and SAT, indicate that HS GPA is a small positive predictor of having eligible AP scores (in particular for AP Chemistry), SAT Reading is a small predictor (particularly for AP Biology), and SAT Math varies from being a small (AP Biology) to large predictor (AP Chemistry and AP Physics). The one salient exception to the predictiveness of SAT Math comes from an institution requiring a five in Physics and having relatively few students meeting the sample size threshold. Table 2 describes all meta-regression coefficients. Overall, we find that having eligible AP credit 
scores is somewhat confounded with various systemic inequities apparent during the K-12 years. Thus, these variables need to be accounted for when examining the impact of skipping on subsequent course performance.

[Table 3 about here]

\section{Course skipping patterns (RQ2)}

Examination of the patterns for RQ2 across courses and institutions reveals broad ranges in the proportion of both students who were eligible to skip (1\% to 38\%) and students choosing to skip the introductory course $(<10 \%$ to $>99 \%$; Figure $2 \mathrm{~A})$. Interestingly, in only a few cases did more than $80 \%$ of skip-eligible students choose to skip the course. These patterns suggest not only variation in departmental policies allowing students to earn AP credit but also in the institutional knowledge and (informal or formal) academic advising available to students in applying their AP credits towards their degree progression. Often, the majority of students, especially within Biology but also in Chemistry course sequences, seem to have received advice to enroll in courses they could have skipped. This is potentially an inequity problem as the lack of consistent guidelines can allow biases in informal networks or individual advisors to have a strong effect on student decision-making processes. This issue is especially important given research showing systemic problems with college advising (Zhang, 2016).

[Figure 2 about here]

However, the logistic regression models did not indicate sizable differences across most different demographic variables in predicting whether skip-eligible students actually skip a course (Figure 2B; Table 2). Notably though, in Biology, first-generation students were more likely to skip when eligible. Confidence intervals were often large and there was never 
statistically significant heterogeneity in effects because sample sizes were somewhat small for those heterogeneity analyses. This is particularly true for institutions with relatively few firstgeneration college students, low-income students, or racially marginalized students.

HS GPA, SAT Math, and SAT Reading performance did not significantly predict course skipping across disciplines either, with SAT Reading representing the only exception in Physics. Overall, we did not find general trends of inequalities for skipping courses for students with skipeligible scores. Combined with the small demographic effects on having skip-eligible scores at these institutions, if skip eligibility thresholds were lowered at these institutions, we expect that equal proportions of students by demographic variables would take advantage of the increased skip opportunities.

\section{Impact of skipping introductory science courses (RQ3)}

When examining all students enrolled in the selected science gateway course series (Figure 3, top panel), we find that performance in the second Biology gateway course is nearly identical between those who skip and those who do not. Interestingly, for Chemistry and Physics, students who skipped actually outperformed students who took the first course with a moderateto-large effect size. Also, there is no indication of significant heterogeneity across the examined institutions within each discipline.

While the matching technique used in this analysis of the full sample of students controlled for many potentially confounding factors, it could not directly control for depth of interest and experience in the discipline as the full sample analysis could not include the presence of an AP experience or performance on an AP exam. The analyses that focused on skipeligible students (Figure 3, bottom panel) controlled for this more directly because it only included students with advanced disciplinary experiences in high school by directly matching on 
their AP performance. Meta-regressions indicate no overall significant differences in subsequent course performance between students who skipped the first course and those who do not across all disciplines (Table 2). However, there was significant heterogeneity of this effect across institutions for Biology. Also, students skipping the first gateway Biology course tend to perform worse in the second course, particularly for a cutoff score of 3.

[Figure 3 about here]

\section{Discussion}

This large-scale study offers unique insights into the higher education landscape within large public research institutions. It represents the first independent, peer-reviewed study that uses advanced quantitative research methodologies to examine a common AP credit policy offering students AP credit to replace introductory college courses. This paper is also the first to examine equity at the level of eligible AP scores within science pathways at selective public research institutions and the first to examine equity in terms of choosing to skip courses when eligible. Policy decisions can have complex and unintended consequences for students overall or important subgroups of students, and thus it is important for policy makers to be informed about potential factors that might exacerbate inequities in the system. In the current contexts, the equity analyses critically showed that there were only very small demographic differences in which students had eligible AP scores and effectively no demographic differences in terms of which students chose to skip courses when eligible.

Before discussing the implications of these findings, we first note some important limitations that should be considered when interpreting these findings. Methodologically, propensity score weighting can only adjust for observed features. Therefore, it may not account for hidden biases correlated with students who chose to skip a course they are eligible to skip 
(e.g., motivational variables such as interest in the discipline). That said, those motivational variables are correlated with academic performance variables included in models and thus are not completely unaccounted for. Future research might use regression discontinuity designs in datasets with larger numbers of skip-eligible students to generate treatment effect estimations. Also, the nature of public research universities will likely limit the generalizability to all universities in the nation. Given the educational inequalities at the national level for access to the AP program (Ackerman et al., 2013; Fischer, Fishman, et al., 2020), it is important to examine whether the patterns hold for underrepresented students at less selective institutions where overall student performance and retention rates are typically lower. University policies should, at the very minimum, not exacerbate inequalities that occur in the K-12 environment. We also acknowledge limitations that institutional data has in capturing important nuance in race and ethnic diversity, gender, or the educational context the student grew up in. There may be further dimensions of inequity that would emerge with data that allow for a more nuanced analysis.

Overall, the main finding that using AP credit to skip the first course does not adversely affect student performance in subsequent gateway courses has implications for educational stakeholders across the nation as millions of students take AP examinations every year (The College Board, 2020b). Importantly, when considering all students (including students who did not take AP examinations), students who skip tend to perform better on subsequent courses compared to students who did not take AP exams or took AP exams but did not skip. When restricting the analysis to skip-eligible students (they took the corresponding AP exam and earned a passing score), the effect of actually skipping the course is negligible but, importantly, students who skip do not seem to be disadvantaged. This is a remarkable given the broad range 
of departmental AP policies and differences in institutional demographics and contexts represented.

While there was some meaningful heterogeneity in these performance effects across disciplines and institutions, this seemed to matter only in Biology. This increased heterogeneity in Biology may be explained through the flexibility in course orders. Whereas the course series in general Chemistry and Physics are mostly stable in terms of what content is covered in the first versus second course, there is a lot more variation in Biology courses sequences. For example, sometimes cell biology and ecology content were in different course sequence order across institutions. As a result, the content knowledge that students may acquire in AP Biology may be differentially important for course performance depending on which content is being skipped.

Importantly, our findings are consistent with those previously obtained (Jagesic \& Wyatt, 2018; Keng \& Dodd, 2008; Morgan \& Klaric, 2007; Wyatt et al., 2018), which used simple correlation or regression methods containing very few control variables and using methods that are less able to recover causal relationships than propensity score matching. This consistency suggests that our findings may also apply to the broader set of institutions examined in those prior studies. This indicates that prior AP experience allows students to perform better in subsequent courses compared to students without comparable AP experience while also avoiding potential negative effects of not taking the first course in science course sequences.

As large institutional data sets become increasingly available to universities to aid datadriven educational policy-making processes (Fischer, Pardos, et al., 2020), we encourage institutions to replicate these analyses at their campus to evaluate their AP policies and potential inequities. Further, we encourage institutions to use the methodological approach used in this 
study to examine other placement decisions affecting large numbers of students based on IB scores, courses taken at community colleges, and internal course placement exams. The GitHub repository of this study (<REMOVED FOR PEER-REVIEW $>$ ) supplementing this article provides in-depth analysis scripts for researchers to aid this process. Included in the repository are methods for: (a) creating aligned variables from institutional data that typically differ in their collection and organization; (b) selecting and aligning courses sequences given the wide variety in alternative pathways institutions often offer (specific to colleges, majors, non-majors, or honors); (c) formally analyzing and representing patterns across institutions without transferring student-level data across institutions, and (d) attending to equity of credit access and use for course skipping.

Although the potential impacts of not taking the first course in a science course sequence are most immediate on the corresponding subsequent course, future research may also investigate impacts of AP credit policies on more distal college success factors including course taking patterns (Gurantz, 2021), graduation rates, terms-to-degree, and time-to-degree, as well as labor market outcomes. Each course's specific policy on its own is unlikely to have large effects on the overall population, but collectively changing policies across an institution does have the potential to substantially change those large grain-size variables.

Implications of this study for educational stakeholders are two-fold and the two parts should be jointly considered. First, on the supply side, school districts and educational policy makers should ensure equitable access to the AP program and high-quality AP instruction, particularly in locations with traditionally lower access to the AP program. Such investments will likely benefit students not only in their college admission process but also during their college career once they are admitted. Second, on the receiving side, departmental and university 
administrators should carefully review their formal and informal AP credit policies. If only high scores are accepted, the rationale for that decision should be empirically evaluated and potentially reconsidered. Similarly, if few students are choosing to skip courses when eligible to skip, the underlying rationale for those decisions should be investigated; if students are being encouraged to take the first course in the sequence, it should not be for fear of poor performance in the second course. Our study encourages departments to continue with policies that award college credit for passing AP scores, or to explore the adoption of such policies as students do not seem negatively affected by skipping the first course in science course sequences.

\section{References}

Ackerman, P. L., Kanfer, R., \& Calderwood, C. (2013). High School Advanced Placement and Student Performance in College: STEM Majors, Non-STEM Majors, and Gender Differences. Teachers College Record, 115, 1-43.

Allen-Ramdial, S.-A. A., \& Campbell, A. G. (2014). Reimagining the pipeline: Advancing STEM diversity, persistence, and success. BioScience, 64(7), 612-618. https://doi.org/10.1093/biosci/biu076

Asai, D. J. (2020). Race Matters. Cell, 181(4), 754-757. https://doi.org/10.1016/j.cell.2020.03.044

Austin, P. C. (2011). An introduction to propensity score methods for reducing the effects of confounding in observational studies. Multivariate Behavioral Research, 46(3), 399-424. https://doi.org/10.1080/00273171.2011.568786

Avery, C., Gurantz, O., Hurwitz, M., \& Smith, J. (2016). Shifting college majors in reponse to Advanced Placement exam scores (NBER Working Paper No. 22841). National Bureau of Economic Research. 
Burnett, A., \& Burkander, P. (2021). Advanced Placement Participation, Staffing, and Staff Training in the District of Columbia Public Schools (REL 2021-077; p. 12). U.S. Department of Education.

Card, D., \& Rothstein, J. (2007). Racial segregation and the black-white test score gap. Journal of Public Economics, 91(11-12), 2158-2184. https://doi.org/10.1016/j.jpubeco.2007.03.006

Chajewski, M., Mattern, K. D., \& Shaw, E. J. (2011). Examining the role of Advanced Placement exam participation in 4-year college enrollment. Educational Measurement: Issues and Practice, 30(4), 16-27.

Chen, X. (2013). STEM attrition: College students' paths into and out of STEM fields (Statistical Analysis Report NCES 2014-001). National Center for Education Statistics, Institute of Education Sciences, U.S. Department of Education.

Conger, D., Long, M. C., \& Iatarola, P. (2009). Explaining race, poverty, and gender disparities in advanced course-taking. Journal of Policy Analysis and Management, 28(4), 555-576. https://doi.org/10.1002/pam.20455

Cromwell, A., McClarty, K. L., \& Larson, S. J. (2013). College readiness indicators. Bulletin, 25, $1-8$.

Dehejia, R. H., \& Wahba, S. (2002). Propensity score-matching methods for nonexperimental causal studies. Review of Economics and Statistics, 84(1), 151-161.

Duffy, W. R. (2010). Persistence and performance at a four-year university. The relationship with advanced coursework during high school (P. M. Sadler, G. Sonnert, R. H. Tai, \& K. Klopfenstein, Eds.; pp. 139-163). Harvard Education Press. 
Evans, B. J. (2019). How college students use Advanced Placement credit. American Educational Research Journal, 56(3), 925-954. https://doi.org/10.3102/0002831218807428

Fischer, C., Fishman, B., Levy, A., Eisenkraft, A., Dede, C., Lawrenz, F., Jia, Y., Kook, J., Frumin, K., \& McCoy, A. (2020). When do students in low-SES schools perform betterthan-expected on a high-stakes test? Analyzing school, teacher, teaching, and professional development characteristics. Urban Education, 5(8-9), 1280-1314. https://doi.org/10.1177/0042085916668953

Fischer, C., Pardos, Z. A., Baker, R. S., Williams, J. J., Smyth, P., Yu, R., Slater, S., Baker, R., \& Warschauer, M. (2020). Mining Big Data in Education: Affordances and Challenges. Review of Research in Education, 44(1), 130-160. https://doi.org/10.3102/0091732X20903304

Galla, B. M., Shulman, E. P., Plummer, B. D., Gardner, M., Hutt, S. J., Goyer, J. P., D’Mello, S. K., Finn, A. S., \& Duckworth, A. L. (2019). Why High School Grades Are Better Predictors of On-Time College Graduation Than Are Admissions Test Scores: The Roles of Self-Regulation and Cognitive Ability. American Educational Research Journal, 56(6), 2077-2115. https://doi.org/10.3102/0002831219843292

Griffith, A. L. (2010). Persistence of women and minorities in STEM field majors: Is it the school that matters? Economics of Education Review, 29(6), 911-922. https://doi.org/10.1016/j.econedurev.2010.06.010

Gurantz, O. (2021). How College Credit in High School Impacts Postsecondary Course-Taking: The Role of Advanced Placement Exams. Education Finance and Policy, 16(2), 233255. https://doi.org/10.1162/edfp_a_00298 
Hallett, R. E., \& Venegas, K. M. (2011). Is increased access enough? Advanced Placement courses, quality, and success in low-income urban schools. Journal for the Education of the Gifted, 34(3), 468-487. https://doi.org/10.1177/016235321103400305

Jagesic, S., \& Wyatt, J. (2018). Postsecondary Course Performance of AP® Exam Takers in Subsequent Coursework: Biology, Languages, and Studio Art. The College Board.

Kanno, Y., \& Kangas, S. E. N. (2014). “I'm not going to be, like, for the AP”: English language learners' limited access to Advanced College-preparatory courses in high school. American Educational Research Journal, 51(5), 848-878. https://doi.org/10.3102/0002831214544716

Keng, L., \& Dodd, B. G. (2008). A Comparison of College Performances of AP® and Non-AP Student Groups in 10 Subject Areas (No. 2008-7). The College Board.

Klugman, J. (2013). The Advanced Placement arms race and the reproduction of educational inequality. Teachers College Record, 115(5), 1-34.

Kyburg, R. M., Hertberg-Davis, H., \& Callahan, C. M. (2007). Advanced Placement and International Baccalaureate programs: Optimal learning environments for talented minorities? Journal of Advanced Academics, 18(2), 172-215. https://doi.org/10.4219/jaa2007-357

Lin, C.-H., Borden, V. M. H., \& Chen, J.-H. (2020). A Study on Effects of Financial Aid on Student Persistence in Dual Enrollment and Advanced Placement Participation. Journal of College Student Retention: Research, Theory \& Practice, 22(3), 378-401. https://doi.org/10.1177/1521025117753732 
Maltese, A. V., \& Tai, R. H. (2011). Pipeline persistence: Examining the association of educational experiences with earned degrees in STEM among U.S. students. Science Education, 95(5), 877-907. https://doi.org/10.1002/sce.20441

Means, B., Wang, H., Young, V., Peters, V. L., \& Lynch, S. J. (2016). STEM-focused high schools as a strategy for enhancing readiness for postsecondary STEM programs. Journal of Research in Science Teaching, 53(5), 709-736. https://doi.org/10.1002/tea.21313

Morgan, R., \& Klaric, J. (2007). AP® Students in College: An Analysis of Five-Year Academic Careers (No. 2007-4). The College Board.

Olson, S., \& Riordan, D. G. (2012). Engage to Excel: Producing One Million Additional College Graduates with Degrees in Science, Technology, Engineering, and Mathematics [Report to the President]. Executive Office of the President.

Price, H. E. (2020). The College Preparatory Pipeline: Disparate Stages in Academic Opportunities. American Educational Research Journal. https://doi.org/10.3102/0002831220969138

Roegman, R., \& Hatch, T. (2016). The AP lever for boosting access, success, and equity. Phi Delta Kappan, 97(5), 20-25.

Sadler, P. M., \& Sonnert, G. (2010). High school Advanced Placement and success in college and coursework in the sciences. In P. M. Sadler, G. Sonnert, R. H. Tai, \& K. Klopfenstein (Eds.), AP: A critical examination of the Advanced Placement program (pp. 119-137). Harvard Education Press.

Sadler, P. M., \& Tai, R. H. (2007). Advanced Placement Exam Scores as a Predictor of Performance in Introductory College Biology, Chemistry and Physics Courses. Science Educator, 16(2), 19. 
Schneider, J. (2009). Privilege, equity, and the Advanced Placement program: Tug of war. Journal of Curriculum Studies, 41(6), 813-831. https://doi.org/10.1080/00220270802713613

Scott, T. P., Tolson, H., \& Lee, Y.-H. (2010). Assessment of Advanced Placement participation and university academic success in the first semester: Controlling for selected high school academic abilities. Journal of College Admission, 208, 26-30.

Smith, J., Hurwitz, M., \& Avery, C. (2017). Giving College Credit Where It Is Due: Advanced Placement Exam Scores and College Outcomes. Journal of Labor Economics, 35(1), 67147.

Taliaferro, J. D., \& DeCuir-Gunby, J. T. (2008). African American educators' perspectives on the Advanced Placement opportunity gap. The Urban Review, 40(2), 164-185. https://doi.org/10.1007/s11256-007-0066-6

The College Board. (2020a). Federal and State AP Exam Fee Assistance. https://apcentral.collegeboard.org/ap-coordinators/exam-ordering-fees/exam-fees/federalstate-assistance

The College Board. (2020b). Program Summary Report. https://securemedia.collegeboard.org/digitalServices/pdf/research/2020/Program-Summary-Report2020.pdf

Tienken, C. H. (2012). The Influence of Poverty on Achievement. Kappa Delta Pi Record, 48(3), 105-107. https://doi.org/10.1080/00228958.2012.707499

Warne, R. T., Sonnert, G., \& Sadler, P. M. (2019). The Relationship Between Advanced Placement Mathematics Courses and Students' STEM Career Interest. Educational Researcher, 48(2), 101-111. https://doi.org/10.3102/0013189X19825811 
Wyatt, J., Jagesic, S., \& Godfrey, K. (2018). Postsecondary Course Performance of AP® Exam Takers in Subsequent Coursework. The College Board.

Zhang, Y. (Leaf). (2016). An Overlooked Population in Community College: International Students' (In)Validation Experiences With Academic Advising. Community College Review, 44(2), 153-170. https://doi.org/10.1177/0091552116633293

Acknowledgments: This work received support from Sloan Equity and Inclusion in STEM Introductory Courses (SEISMIC) project funded by the Alfred P. Sloan Foundation and participating institutions. The SEISMIC website is https://www.seismicproject.org. SEISMIC is managed at the University of Michigan for the participating institutions which include Arizona State University, Indiana University, Michigan State University, Purdue University, University of California Davis, University of California Irvine, University of California Santa Barbara, University of Michigan, University of Minnesota, and University of Pittsburgh. The authors would like to thank the following people for their support of this research: members of the larger SEISMIC research project (Timothy McKay and Nita Kedharnath), research team members contributing to early iterations of this work (Mark Umbricht, Yasemin Kalendar, Kyle Whitcomb, and Peter Radcliffe), as well as the many educational stakeholders and administrators involved in the collection, preparation, and curation of the institutional data sets used in this project. The views contained in this article are those of the authors, and not their institutions, the Alfred P. Sloan Foundation, or the College Board. 


\section{Figures and Tables}

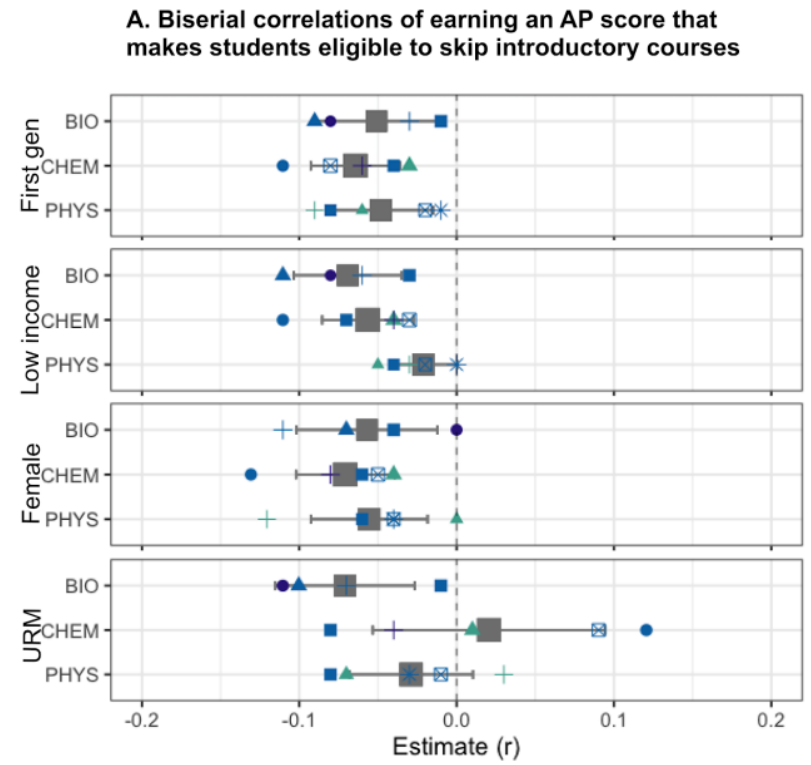

B. Odds Ratios of earning an AP score that makes students eligible to skip introductory courses

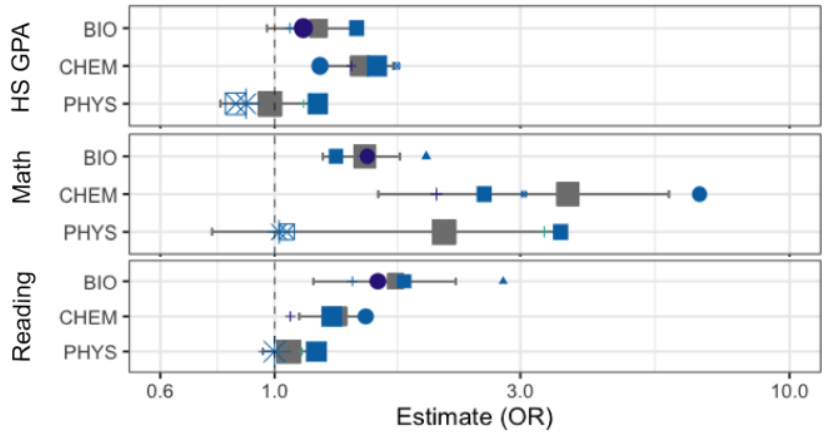

Key

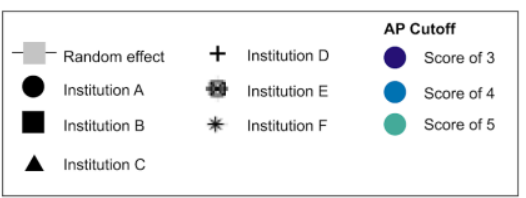

Figure 1. A) Meta-regression biserial correlations of demographic characteristics with earning an AP score that would allow a student to skip the first course in the sequence at their institution. B) Meta-regression Odds Ratios (OR) of HS GPA, SAT Math, and SAT Reading Score with that same skip eligibility (controlling for demographic variables). Point color indicates the cutoff value for AP score required by that institution for that discipline. Point size is proportional to the sample size from each institution. Due to sample size limitations, not all institutions contribute to the estimates for each analysis with more institutions contributing to the correlation analysis in Panel A compared to Panel B. 

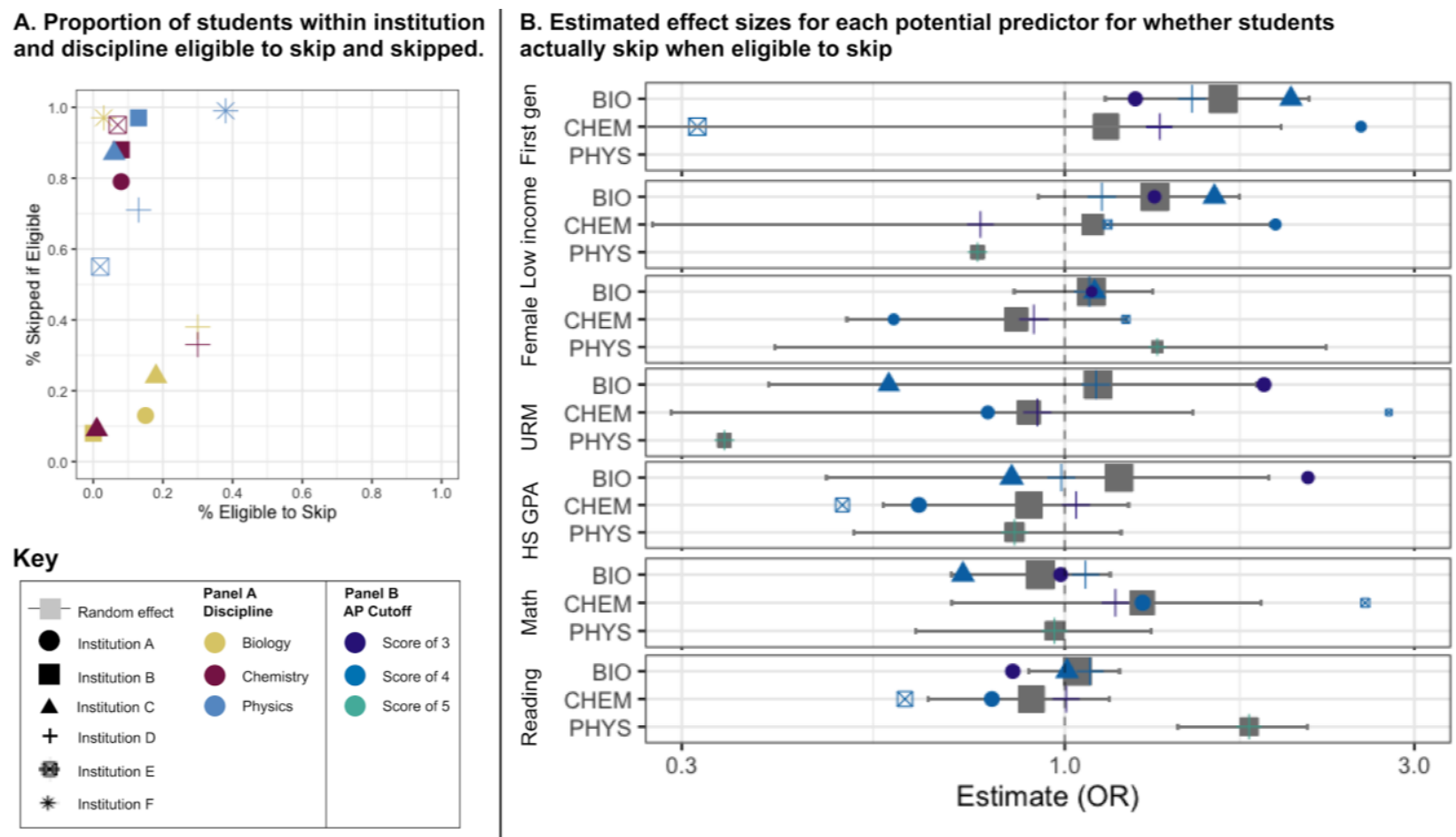

Figure 2. A) Proportion of students at each institution (indicated by shape) and within each discipline (indicated by color) that both earned an AP score that allowed them to skip the introductory course (x-axis) and that chose to actually skip that course when eligible (y-axis). B) Estimated effect sizes $(\mathrm{OR}=$ odds ratios) for each potential predictor for whether students actually skip when eligible to skip. Institution is indicated by shape and AP score cutoff value required for skip eligibility is indicated by point color. Due to sample size limitations, not all institutions contribute to the estimates for each variable. 


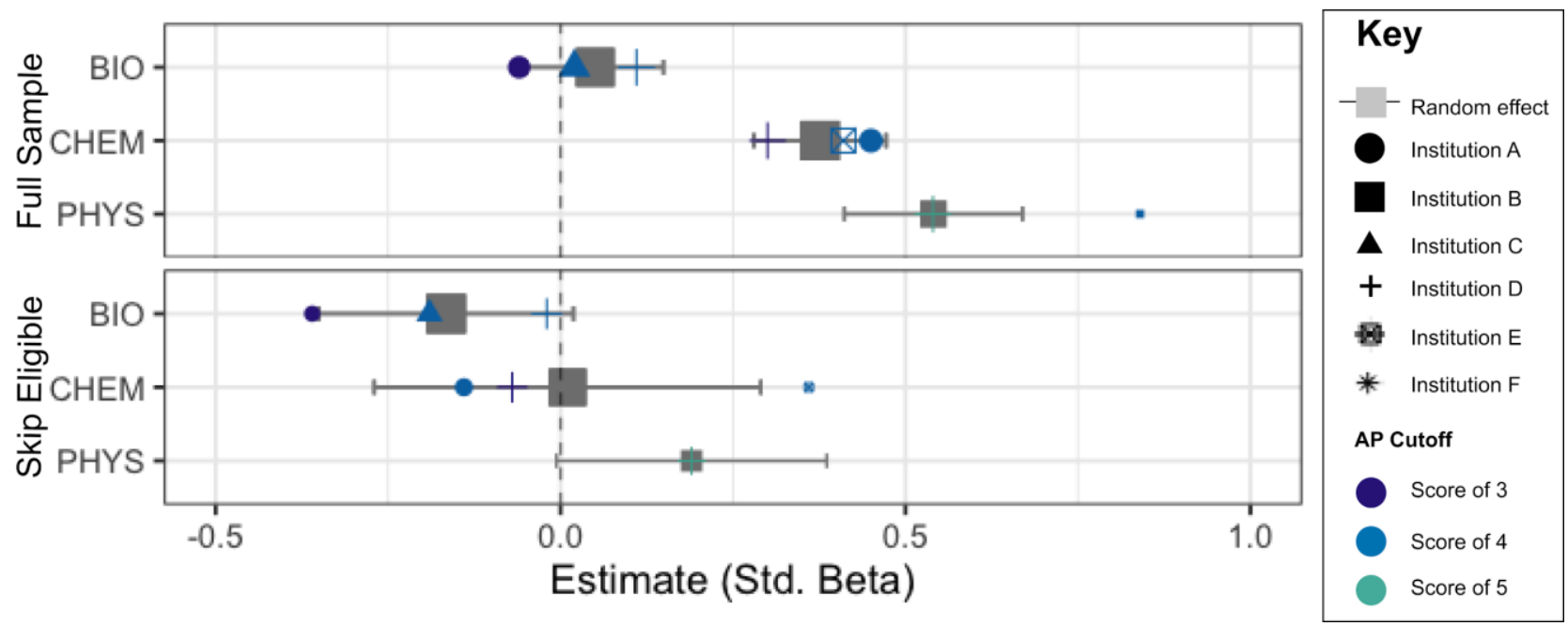

Figure 3. The estimated standardized effect of skipping the first course on the second course grade in each course sequence, for the full sample (top) and for those students who earned a score that made them eligible to skip the first course (bottom) using propensity weights. Due to sample size limitations, not all institutions contribute to the estimates for each analysis. 
Table 1. Descriptive information for all variables by science discipline for each institution with AP credit policies.

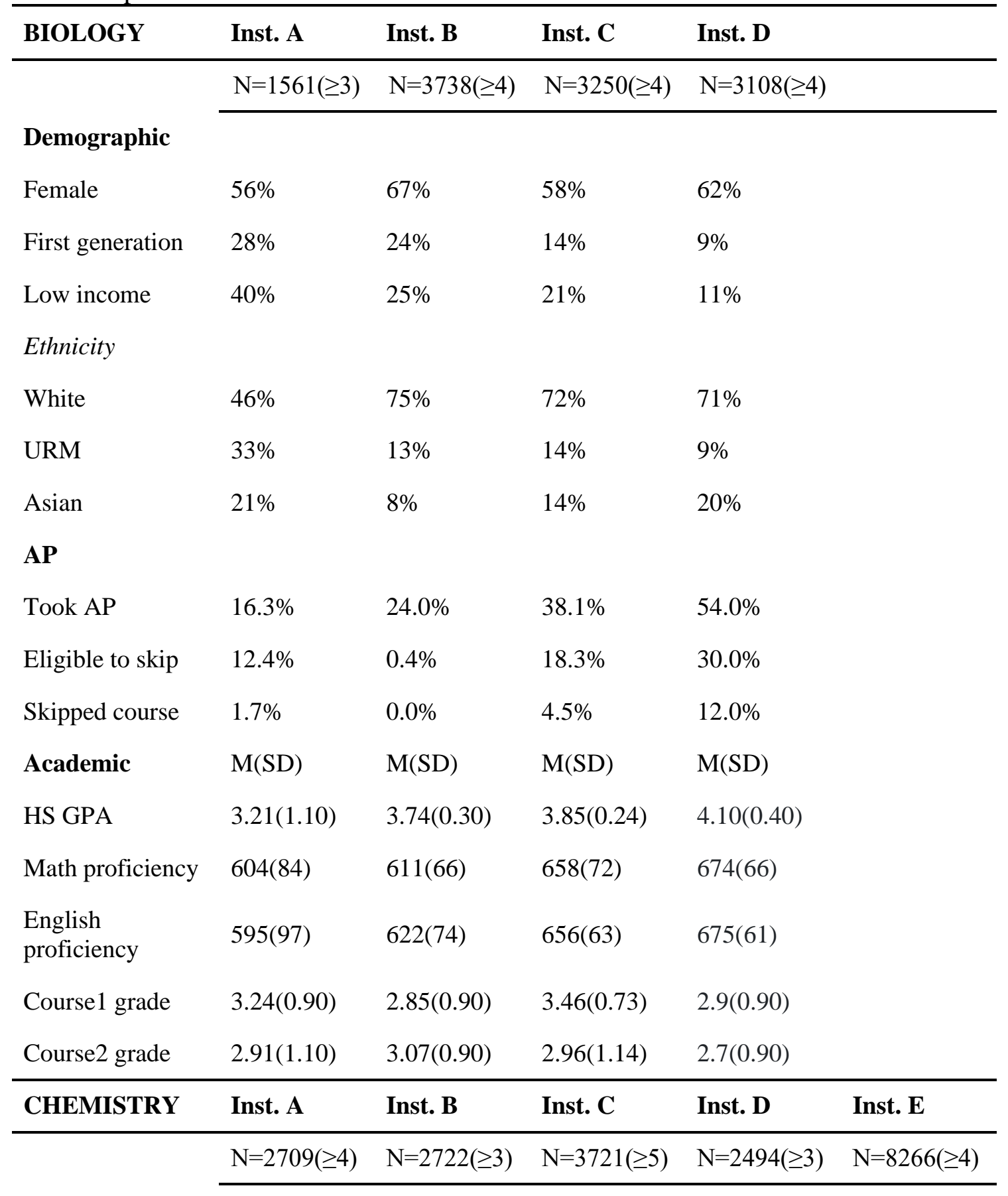

\section{Demographic}

$\begin{array}{llllll}\text { Female } & 57.10 \% & 64.40 \% & 61.00 \% & 59.20 \% & 64.30 \% \\ \text { First generation } & 27.80 \% & 23.80 \% & 14.10 \% & 8.70 \% & 49.00 \% \\ \text { Low income } & 37.40 \% & 26.20 \% & 22.70 \% & 10.40 \% & 43.60 \%\end{array}$


Ethnicity

$\begin{array}{llllll}\text { White } & 50 \% & 70 \% & 72 . & 70 \% & 15 \% \\ \text { URM } & 32 \% & 15 \% & 15 \% & 9 \% & 33 \% \\ \text { Asian } & 18 \% & 10 \% & 13 \% & 21 \% & 52 \%\end{array}$

AP

Took AP

$17.9 \%$

$18.5 \%$

$20.0 \%$

$40.4 \%$

$14.1 \%$

Eligible to skip

$6.0 \%$

$8.4 \%$

$0.6 \%$

$30.2 \%$

$2.0 \%$

Skipped course

$4.7 \%$

$7.3 \%$

$0.1 \%$

$14.0 \%$

$1.6 \%$

Academic

$\mathrm{M}(\mathrm{SD})$

$\mathrm{M}(\mathrm{SD})$

$\mathrm{M}(\mathrm{SD})$

$\mathrm{M}(\mathrm{SD})$

$\mathrm{M}(\mathrm{SD})$

HS GPA

3.17(1.20)

3.77(0.30)

$3.85(0.24)$

$4.10(0.40)$

$3.98(0.22)$

Math proficiency

618(80)

618(71)

653(71)

682(64)

597(81)

English

proficiency

609(97) 623(71)

651(64)

680(57.5)

$555(81)$

Course1 grade $\quad 3.08(0.80)$

3.17(0.90) 2.97(1.01)

$3.00(0.80)$

$2.67(0.87)$

Course 2 grade

2.98(1.20)

2.99(1.10)

2.04(1.52)

$2.80(0.90)$

$2.39(1.10)$

\begin{tabular}{llllcc}
\hline PHYSICS & Inst. F & Inst. B & Inst. C & Inst. D & Inst. E \\
\hline & $\mathrm{N}=3911(\geq 5)$ & $\mathrm{N}=2122(\geq 4)$ & $\mathrm{N}=547(\geq 5)$ & $\mathrm{N}=1724(\geq 5)$ & $\mathrm{N}=3090(\geq 4)$ \\
\hline
\end{tabular}

\section{Demographic}

Female

$24 \%$

$24 \%$

$31 \%$

$31 \%$

$26 \%$

First generation

$8 \%$

$14 \%$

$12 \%$

$6 \%$

$57 \%$

Low income

$12 \%$

$17 \%$

$18 \%$

$7 \%$

$36 \%$

Ethnicity

White

$62 \%$

$80 \%$

$80 \%$

$85 \%$

$20 \%$

URM

$9 \%$

$8 \%$

$9 \%$

$5 \%$

$29 \%$

Asian

$19 \%$

$9 \%$

$12 \%$

$10 \%$

$52 \%$

\section{AP}

Took AP

$6.0 \%$

$26.0 \%$

$12.0 \%$

$32.0 \%$

$16.5 \%$

Eligible to skip

$36.3 \%$

$12.7 \%$

$5.5 \%$

$13.0 \%$

$2.5 \%$

Skipped course $\quad 36.3 \%$

$12.2 \%$

$4.8 \%$

$14.6 \%$

$1.7 \%$ 


\begin{tabular}{llllll} 
Academic & $\mathrm{M}(\mathrm{SD})$ & $\mathrm{M}(\mathrm{SD})$ & $\mathrm{M}(\mathrm{SD})$ & $\mathrm{M}(\mathrm{SD})$ & $\mathrm{M}(\mathrm{SD})$ \\
HS GPA & $3.80(0.80)$ & $3.81(0.30)$ & $3.86(0.24)$ & $4.20(0.40)$ & $4.03(0.23)$ \\
$\begin{array}{l}\text { Math proficiency } \\
\text { English }\end{array}$ & $739(46)$ & $672(66)$ & $700(66)$ & $721(52)$ & $650(76)$ \\
$\begin{array}{l}\text { proficiency } \\
\text { Course1 grade }\end{array}$ & $521(109)$ & $645(76)$ & $680(58)$ & $697(55)$ & $587(84)$ \\
\begin{tabular}{l} 
Course2 grade \\
\hline
\end{tabular} & $2.78(1.70)$ & $3.32(0.70)$ & $3.23(0.85)$ & $2.8(0.70)$ & $3.03(0.78)$ \\
\hline
\end{tabular}


Table 2. AP score requirements to skip the first course in the course sequence across disciplines and institutions.

\begin{tabular}{lcccccc}
\hline & Inst. A & Inst. B & Inst. C & Inst. D & Inst. E & Inst. F \\
\hline Biology & 3 & 4 & 4 & 4 & No skip & 4 \\
Chemistry & 4 & 3 & 5 & 3 & 4 & No skip \\
Physics & No skip & 4 & 5 & 5 & 4 & 5 \\
\hline
\end{tabular}


Table 3. Meta Regression Results

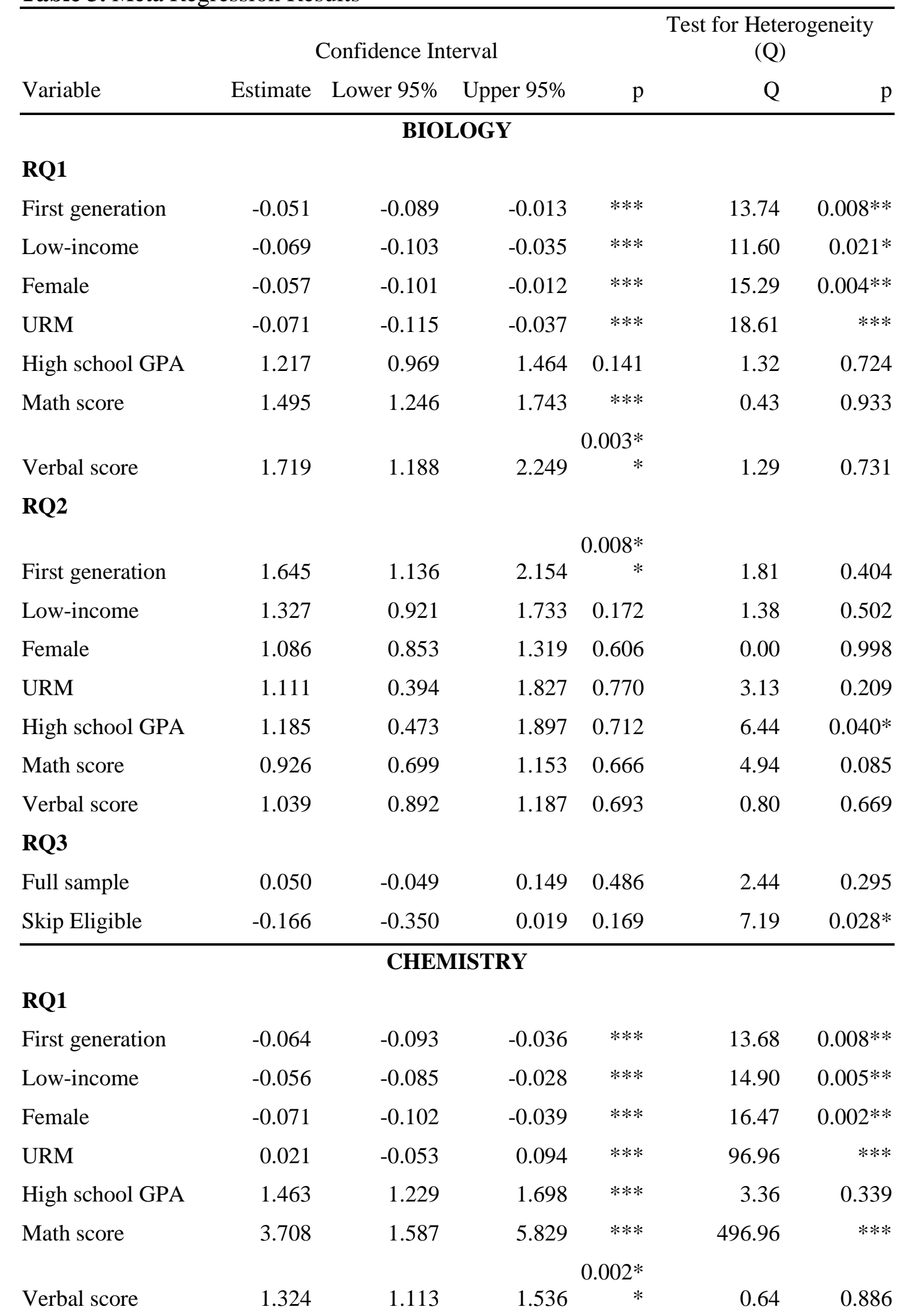




\section{RQ2}

First generation

$\begin{array}{ll}1.139 & -0.008 \\ 1.092 & 0.274 \\ 0.858 & 0.504 \\ 0.893 & 0.290 \\ 0.894 & 0.566 \\ 1.276 & 0.701 \\ 0.900 & 0.650\end{array}$

$2.285 \quad 0.795$

$5.11 \quad 0.078$

Low-income

Female

URM

High school GPA

Math score

Verbal score$$
1.910 \quad 0.785
$$$$
2.22 \quad 0.33
$$$$
1.212 \quad 0.632
$$

0.56

0.757

$$
1.495 \quad 0.769
$$

0.05

0.977

$1.222 \quad 0.677$

$2.64 \quad 0.268$

RQ3

Full sample

$$
0.376
$$

0.280

$1.850 \quad 0.492$

$1.18 \quad 0.554$

Skip Eligible

0.010

$-0.270$

$0.472 \quad * * *$

3.58

0.167

\section{PHYSICS}

\section{RQ1}

First generation

$$
-0.048
$$

$$
-0.082
$$

$-0.015 \quad * * *$

Low-income

$-0.021$

$-0.043$

$0.002 * * *$

1.90

0.387

Female

$$
-0.056
$$

$-0.093$

$-0.019 \quad * * *$

URM

$-0.029$

$-0.068$

$0.010 * * * *$

High school GPA

$$
0.979
$$

0.786

1.1720 .798

$3.510 \quad 0.123$

2.133

0.756

$1.180 \quad 0.417$

5.55

0.062

Math score

1.065

0.950

RQ2

$\begin{array}{lcccccc}\text { Low-income } & 0.760 & -0.531 & 2.051 & 0.581 & - & - \\ \text { Female } & 1.337 & 0.402 & 2.272 & 0.677 & - & - \\ \text { URM } & 0.343 & 0.285 & 1.940 & 0.492 & - & - \\ \text { High school GPA } & 0.854 & 0.515 & 1.193 & 0.614 & - & - \\ \text { Math score } & 0.968 & 0.625 & 1.311 & 0.677 & - & - \\ \text { Verbal score } & 1.784 & 1.427 & 2.141 & 0.492 & - & - \\ \text { RQ3 } & & & & & 0.03 & 0.855 \\ \text { Full sample } & 0.541 & 0.412 & 0.670 & * * * & - & - \\ \text { Skip Eligible } & 0.190 & -0.006 & 0.386 & 0.131 & \end{array}$

Notes. $* p<.05 ; * * p<.01 ; * * * p<.001$. 